\title{
TRANSPOR IODIN MELALUI MEMBRAN KLOROFORM DENGAN TENIK MEMBRAN CAIR FASA RUAH
}

\author{
Refinel, Zaharasmi Kahar, dan Sukmawita \\ Jurusan Kimia FMIPA Universitas Andalas \\ E-mail: refinel@yahoo.com
}

\begin{abstract}
The transport of iodine through a bulk liquid membrane containing chloroform as the solvent and alkaline sodium sulfite solution as the receiving phase was studied .Iodine transport was performed by bulk liquid membrane technique consist of $10 \mathrm{~mL} \mathrm{I} / \mathrm{KI}$ solution as feed phase, $\mathrm{Na}_{2} \mathrm{SO}_{3}(20 \mathrm{~mL})$ and $\mathrm{NaOH}$ solution as receiving phase, and chloroform $(30 \mathrm{~mL})$ as membrane phase which was stirred $100 \mathrm{rpm}$. The presence of iodine both in feed and receiving phase then where determined by Spectrophotometer UV-Vis with $\lambda \max$ at $567 \mathrm{~nm}$. The optimum conditions for iodine transport investigated from this work are $4 \times 10^{-3} \mathrm{~N}, \mathrm{pH} 4$ in feed phase, $\mathrm{pH} 9$ in receiving phase, $\mathrm{I}_{2}:$ KI ratio in feed phase $(2: 5)$, and a stirring duration is 180 minutes. As conclusion the bulk liquid membrane technique with $\mathrm{Na}_{2} \mathrm{SO}_{3}$ and $\mathrm{NaOH}$ as receiving and acception substances is potential for iodine transport resulting $78.6 \%$ of iodin transport.
\end{abstract}

Keywords: Iodine, transport, chloroform, bulk liquid membrane, $\mathrm{Na}_{2} \mathrm{SO}_{3}, \mathrm{NaOH}$

\section{PENDAHULUAN}

Iodin dan senyawanya memiliki aplikasi yang luas di bidang industri, kesehatan, sanitasi, nutrisi dan lain. Pemakaian iodin dalam dunia kesehatan dapat memberikan dampak positif dan negatif terhadap lingkungan pemakaiannya. Dampak negatif dari limbah iodin salah satunya ditemukan di rumah sakit. Iodin biasanya dipakai secara berlebihan terutama pada proses operasi sebagai obat dan antiseptik, sehingga dilingkungan rumah sakit sering ditemukan limbah cair yang mengandung senyawa $\operatorname{iodin}^{[1]}$. Untuk itu diperlukan solusi dalam menanggulangi pencemaran ini.

Penelitian untuk memonitor dan memisahkan iodin yang terlarut dalam air sudah dilakukan oleh Betsabe dkk, yaitu melalui ekstraksi pelarut dan dengan metoda membran cair fasa ruah. Iodin yang terlarut dalam air sebagai fasa sumber dengan cara mentranspor iodin $\left(\mathrm{I}_{2} / \mathrm{KI}\right)$ melalui membran berupa minyak tanah (kerosin) ke fasa berair lain yang mengandung $\mathrm{NaOH}$ dan $\mathrm{Na}_{2} \mathrm{SO}_{3}$ sebagai fasa penerima. Dari hasil penelitiannya di dapatkan waktu transpor iodin ke fasa penerima dengan waktu yang cukup lama yaitu 28 jam dan transpor sebanyak $85 \%{ }^{[2]}$.

Pada penelitian ini dicoba untuk menata ulang dan memodifikasi sistem transpor diatas dengan memanfaatkan kelarutan iodin dalam kloroforom sebagai fasa membran. Hal ini disebabkan iodin larut baik dalam pelarut kloroform $(\mathrm{Kd}=340)^{[3]}$. Sejauh mana kemampuan iodin untuk tertranspor melalui proses difusi antar fasa dari larutan berair $\mathrm{I}_{2} / \mathrm{KI}$ sebagai fasa sumber ke dalam kloroform sebagai membran dan menuju fasa penerima $\mathrm{Na}_{2} \mathrm{SO}_{3}$ dalam suasana basa $\mathrm{NaOH}$ dilakukan pengkajian lebih lanjut untuk diteliti dengan harapan transpor iodin dapat berjalan lebih cepat.

\section{METODOLOGI PENELITIAN}

\section{Alat dan Bahan}

Alat-alat yang digunakan pada penelitian ini adalah Spektrofotometer UV-Vis (spektronik 20 D), pH-meter (Hanna Instrument), sel membran cair fasa ruah, stopwatch, magnetik 
stirrer, neraca analitik (ainsworth), dan peralatan-peralatan gelas lainnya.

Bahan yang digunakan pada penelitian ini adalah kloroform $\left(\mathrm{CHCl}_{3}\right)$, iodium $\left(\mathrm{I}_{2}\right)$, kalium iodida (KI), natrium sulfit $\left(\mathrm{Na}_{2} \mathrm{SO}_{3}\right)$, kalium bikromat $\left(\mathrm{K}_{2} \mathrm{Cr}_{2} \mathrm{O}_{7}\right)$, asam klorida $(\mathrm{HCl})$, natrium hidroksida $(\mathrm{NaOH})$, kalium persulfat $\left(\mathrm{K}_{2} \mathrm{~S}_{2} \mathrm{O}_{8}\right)$, natrium tiosulfat $\left(\mathrm{Na}_{2} \mathrm{~S}_{2} \mathrm{O}_{3} .5 \mathrm{H}_{2} \mathrm{O}\right)$, amilum, dan aquades.

Penentuan Transpor Iodin Melalui Teknik Membran Cair Fasa Ruah

Percobaan transpor dilakukan dengan memakai metode Safavi ${ }^{[4,8,9,10,]}$. Ke dalam beaker gelas $100 \mathrm{~mL}$ (diameter 4,8 cm) dimasukkan fasa membran yaitu $30 \mathrm{~mL}$ larutan kloroform, kemudian pada larutan fasa membran dicelupkan sebuah tabung kaca silindris (diameter dalam $3 \mathrm{~cm}$ ) yang ke dalamnya dipipetkan $10 \mathrm{~mL}$ larutan fasa sumber $\mathrm{I}_{2} / \mathrm{KI} 4 \times 10^{-3} \mathrm{~N}$ yang $\mathrm{pH}$ larutan telah diatur terlebih dahulu. Di luar tabung kaca silindris dipipetkan $20 \mathrm{~mL}$ larutan fasa penerima $\mathrm{Na}_{2} \mathrm{SO}_{3} 8 \times 10^{-3} \mathrm{~N}$ dan juga telah diatur $\mathrm{pH}$ larutannya. Teknis operasi dilakukan melalui pengadukan dengan menggunakan magnetik stirer pada kecepatan $\pm 100 \mathrm{rpm}$ selama 1 jam. Proses transpor iodin dari fasa sumber - fasa membran - fasa penerima berlangsung melalui proses difusi. Setelah pendiaman selama 10 menit, fasa penerima dan fasa sumber diambil untuk diukur nilai absorbannya dengan alat spektrofotometer UV-Vis, sehingga didapatkan konsentrasi iodin sisa di fasa sumber dan yang berhasil sampai ke fasa penerima dengan bantuan kurva kalibrasi iodin. Prosedur yang sama dilakukan untuk mendapatkan optimasi terhadap parameter yang diuji antara lain, pengaruh $\mathrm{pH}$ fasa sumber, pengaruh $\mathrm{pH}$ fasa penerima, pengaruh konsentrasi (perbandingan $\mathrm{I}_{2}: \mathrm{KI}$ ) dalam fasa sumber dan pengaruh lama waktu pengadukan.

\section{HASIL DAN PEMBAHASAN}

Pengaruh pH Fasa Sumber terhadap Transpor Iodin
Pengaturan $\mathrm{pH}$ dalam fasa sumber ditujukan untuk mengatur kesetimbangan iodin dalam air untuk dapat ditranspor dalam bentuk molekul ke fasa membran kloroform. Menurut Betsabe, dalam larutan air iodin akan terhidrolisis seperti reaksi berikut:

$$
\mathrm{I}_{2(\mathrm{aq})}+\mathrm{H}_{2} \mathrm{O}_{(\mathrm{l})} \longleftrightarrow \mathrm{HIO}_{(\mathrm{aq})}+\mathrm{I}^{-}{ }_{(\mathrm{aq})}+\mathrm{H}^{+}{ }_{(\mathrm{aq})} \text {. }
$$

Pada pH 5 hampir 99\% iodin terdapat dalam bentuk campuran $\mathrm{I}_{2}$ dan bentuk ionik, sehingga iodin tidak larut banyak dalam pelarut organik ${ }^{[1,2]}$. Pengaturan $\mathrm{pH}$ ditujukan untuk mendifusi $\mathrm{I}_{2}$ dalam bentuk molekul ke dalam fasa membran kloroform. Oleh karena itu, dilakukan penelitian terhadap variasi $\mathrm{pH}$ larutan di fasa sumber dari $\mathrm{pH} 3$ - 6. Pada rentang $\mathrm{pH}$ tersebut (kondisi asam di fasa sumber) merupakan kondisi yang tepat untuk mendifusikan iodin dalam bentuk molekul ke fasa membran. Difusi ini terjadi di antarmuka fasa sumber dan fasa membran dalam bentuk reaksi transisi berikut dan terjadi pada $\mathrm{pH}$ tertentu:

$$
\mathrm{I}_{2} / \mathrm{I}^{-}(\mathrm{aq}) \quad \longleftrightarrow \quad \mathrm{I}_{2 \text { (org) }}
$$

$\mathrm{I}_{2}$ memiliki kelarutan yang baik dalam pelarut organik seperti kloroform, benzen, dan lain-lain. Kelarutan $\mathrm{I}_{2}$ didalam kloroform $(\mathrm{Kd}=340)^{[3]}$. Penelitian dilakukan dengan waktu transpor selama 1 jam untuk $\mathrm{pH}$ fasa sumber $3-6$, pH optimum iodin untuk proses transpor melalui difusi reaksi diatas masuk ke membran diperoleh pada $\mathrm{pH}$ fasa sumber 4 dimana iodin tertranspor sebesar $14,41 \%$ dan tersisa di fasa sumber $8,35 \%$. Pada $\mathrm{pH}$ ini difusi iodin ke dalam membran sangat baik dapat dilihat dari warna membran (pink), dimana iodin banyak terekstrak dan terperangkap dalam membran $(77,24 \%)$. Pada $\mathrm{pH}$ kecil dari 4 iodin $\left(\mathrm{I}_{3}^{-}\right)$yang dihasilkan dari reaksi antara $\mathrm{I}_{2}$ dan $\mathrm{I}^{-}$masih stabil dalam fasa sumber sehingga iodin yang tertranspor ke fasa penerima rendah, sedangkan pada $\mathrm{pH}$ lebih besar dari 4 transpor iodin ke fasa penerima kembali mengalami penurunan, karena $\mathrm{pH}$ lebih besar dari 4, iodin terdapat dalam bentuk campuran $\mathrm{I}_{2}$ dan bentuk ionik, dalam kondisi seperti ini iodin tidak larut banyak dalam pelarut organik dan mengakibatkan hanya sedikit 
iodin yang berhasil tertranspor ke fasa penerima $^{[1,2,7]}$.

Pengaruh $\mathrm{pH}$ Larutan di fasa Penerima terhadap Transpor Iodin

Reagen striping dalam fasa penerima yang digunakan adalah $\mathrm{Na}_{2} \mathrm{SO}_{3}$ dan $\mathrm{NaOH}$. Dalam hal ini di antar muka fasa membran dengan fasa penerima, terjadi proses transisi:

$$
\mathrm{I}_{2} \text { (org) } \longleftrightarrow \mathrm{I}_{2} \text { (aq). }
$$

Kemudian diikuti dengan reaksi redoks $\left(\mathrm{I}_{2}\right)$ dengan $\mathrm{Na}_{2} \mathrm{SO}_{3}$ dalam kondisi basa ${ }^{[2,6]}$.

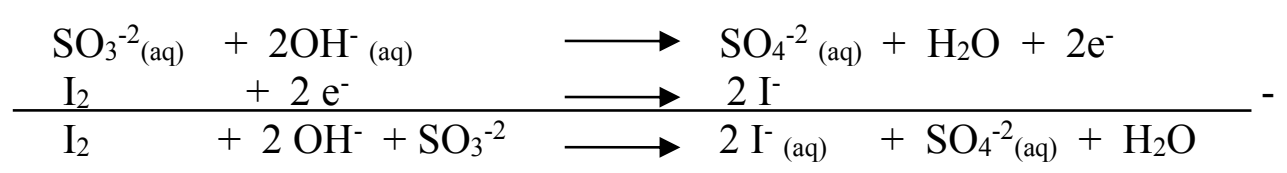

Reaksi dalam bentuk sempurna:

$$
\mathrm{I}_{2 \text { (org) }}+2 \mathrm{NaOH}+\mathrm{Na}_{2} \mathrm{SO}_{3} \longrightarrow 2 \mathrm{NaI}_{(\mathrm{aq})}+\mathrm{Na}_{2} \mathrm{SO}_{4(\mathrm{aq})}+\mathrm{H}_{2} \mathrm{O} \text {. }
$$

Pada kondisi basa di fasa penerima merupakan keadaan yang tepat untuk terjadinya reaksi oksidasi reduksi antara $\mathrm{I}_{2}$ (org) di antarmuka fasa penerima dengan $\mathrm{Na}_{2} \mathrm{SO}_{3}$ dan $\mathrm{NaOH}$. Hasil penelitian yang telah dilakukan $\mathrm{pH}$ optimum untuk terjadinya proses di atas di fasa penerima adalah $\mathrm{pH} 9$ dengan jumlah iodin yang tertranspor sebanyak $21,52 \%$ dan yang tersisa di fasa sumber $8,13 \%$ untuk lama pengadukan 1 jam (Gambar 1). Pada pH 9 merupakan kondisi optimum reaksi redoks antara $\mathrm{I}_{2}$ dan natrium sulfit, sehingga pada $\mathrm{pH}$ kecil dan besar dari 9 jumlah iodin yang tertranspor ke fasa penerima masih rendah.

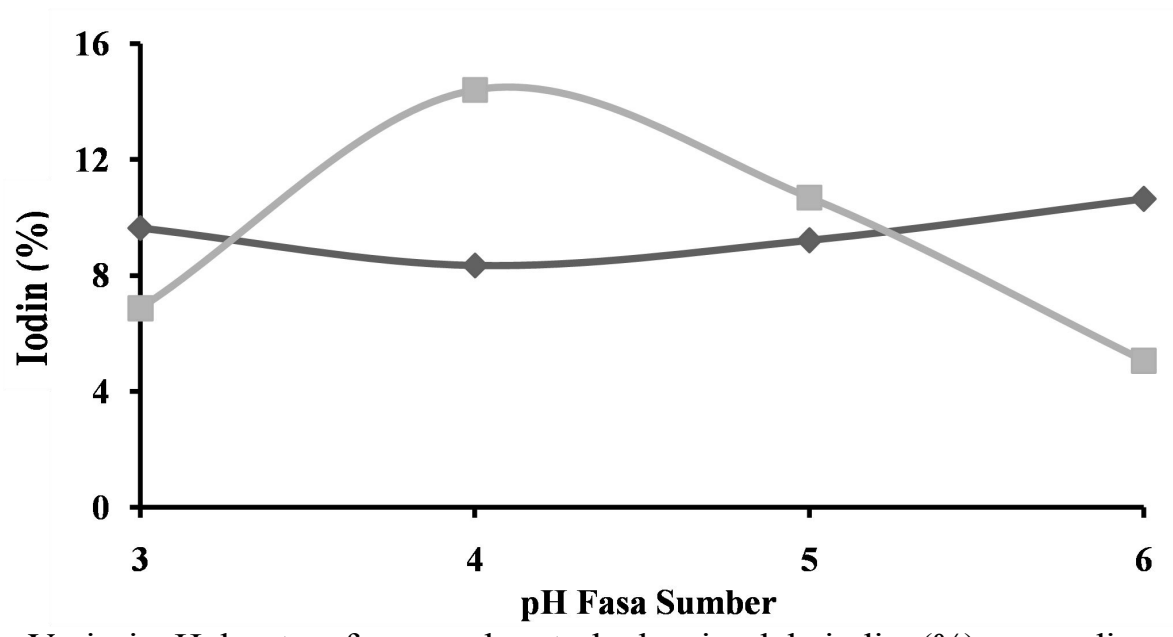

Gambar 1: Variasi pH larutan fasa sumber terhadap jumlah iodin (\%) yang diperoleh di fasa sumber $(\bullet)$ dan fasa penerima ( $\mathbf{\square})$.

Kondisi percobaan : Fasa sumber $10 \mathrm{~mL}\left(\mathrm{I}_{2} / \mathrm{I}^{-}\right) 4 \times 10^{-3} \mathrm{~N}$, fasa membran $30 \mathrm{~mL}$ kloroform, fasa penerima $20 \mathrm{ml} \mathrm{Na} \mathrm{SO}_{3} 8 \times 10^{-3} \mathrm{~N}$ dan $\mathrm{NaOH} \mathrm{pH}$ 10, waktu transpor 1 jam, dan waktu kesetimbangan 10 menit.

Pengaruh Perbandingan Konsentrasi $\mathrm{I}_{2}: \mathrm{KI}$ di Fasa Sumber terhadap Transpor Iodin

$\mathrm{I}_{2}$ mempunyai kelarutan yang sulit larut di dalam air. Untuk melarutkan $\mathrm{I}_{2}$ di fasa sumber digunakan KI yang akan melarutkan $\mathrm{I}_{2}$ menjadi bentuk $\mathrm{I}_{3}^{-}$di fasa air. Ion $\mathrm{I}_{3}^{-}$, iodium, dan ion iodida di dalam air membentuk reaksi yang setimbang sebagai berikut: 


$$
\mathrm{I}_{2(\mathrm{aq})}+\mathrm{I}_{(\mathrm{aq})} \longleftrightarrow \mathrm{I}_{3^{-}(\mathrm{aq})} \text {. }
$$

Kesetimbangan reaksi kelarutan iodin ini dalam bentuk $\mathrm{I}_{3}^{-}$merupakan dasar utama untuk mengekstrak iodin kedalam pelarut organik kloroform (fasa membran ${ }^{[3]}$. Dalam hal ini perlu dicari kondisi yang tepat untuk mempermudah terjadinya proses transisi iodin terekstrak dari fasa sumber ke fasa membran kloroform dan kemudian ke fasa penerima, yakni dengan melakukan pengaturan perbandingan konsentrasi $\mathrm{I}_{2}$ dengan $\mathrm{KI}$ dan pengaturan $\mathrm{pH}$ optimum di fasa sumber. Konsentrasi larutan $\mathrm{I}_{2}$ di fasa sumber dibuat tetap yaitu $4 \times 10^{-3} \mathrm{~N}$, sedangkan konsentrasi larutan KI divariasikan dari $2: 3$ sampai dengan $2: 7^{[3]}$. Nilai konsentrasi KI berturut-turut dihitung untuk perbandingan $\mathrm{I}_{2}: \mathrm{KI}(2: 3)$ adalah $0,006 \mathrm{~N}$; $\mathrm{I}_{2}: \mathrm{KI}(2: 4)$ adalah $0,008 \mathrm{~N} ; \mathrm{I}_{2}: \mathrm{KI}(2: 5)$ adalah $0,01 \mathrm{~N} ; \mathrm{I}_{2}: \mathrm{KI}(2: 6)$ adalah $0,012 \mathrm{~N}$; dan $\mathrm{I}_{2}: \mathrm{KI}(2: 7)$ adalah $0,014 \mathrm{~N}$.
Gambar 3 dapat dilihat bahwa perbandingan $\mathrm{I}_{2}$ : KI yang optimum untuk kelarutan iodin dalam air adalah dengan perbandingan $(2: 5)$ atau konsentrasi $\mathrm{KI} 0,01 \mathrm{~N}$, dimana hasil transpor ke fasa penerima naik sebesar $21,80 \%$, sedangkan sisa di fasa sumber turun mencapai $8,02 \%$. Pada perbandingan $\mathrm{I}_{2}: \mathrm{KI}$ di bawah $(2: 5) \%$ transpor rendah, hal ini karena belum tercapainya jumlah KI optimum yang diperlukan untuk melarutkan $\mathrm{I}_{2}$ (kelarutan terhadap $\mathrm{I}_{2}$ masih rendah) dalam air. Transpor iodin di fasa penerima kembali mengalami penurunan pada perbandingan $\mathrm{I}_{2}$ : KI besar dari (2:5), karena jumlah KI yang dibutuhkan untuk melarutkan $\mathrm{I}_{2}$ sudah melebihi keadaan optimumnya yang mengakibatkan ion $\mathrm{I}_{3}^{-}$yang dihasilkan dari reaksi antara $I_{2}$ dan KI sangat stabil dalam pelarut air (fasa sumber), sehingga jumlah iodin yang berhasil diekstrak ke dalam membran untuk ditranspor ke fasa penerima sedikit.

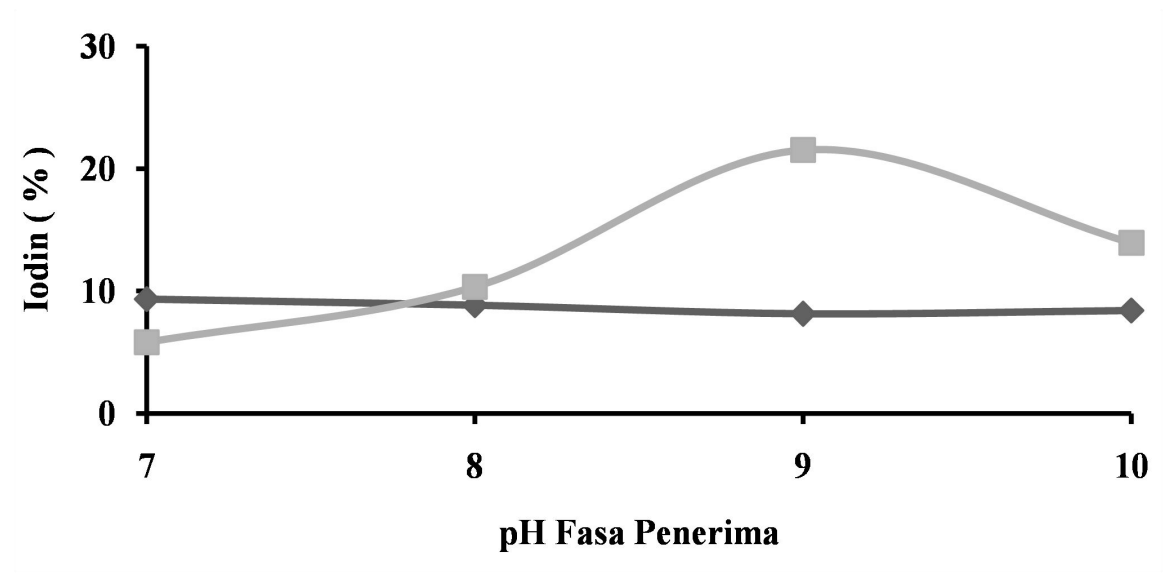

Gambar 2. Variasi $\mathrm{pH}$ larutan fasa penerima terhadap \% iodin yang diperoleh di fasa sumber ( $\diamond)$ dan fasa penerima ( $\mathbf{\square})$.

Kondisi percobaan: Fasa sumber $10 \mathrm{~mL}\left(\mathrm{I}_{2} / \mathrm{I}^{-}\right) 4 \times 10^{-3} \mathrm{~N} \mathrm{pH} 4$, fasa membran $30 \mathrm{~mL}$ kloroform, fasa penerima $20 \mathrm{ml} \mathrm{Na}_{2} \mathrm{SO}_{3} 8 \times 10^{-3} \mathrm{~N}$ dan $\mathrm{NaOH}$, waktu transpor 1 jam, dan waktu kesetimbangan 10 menit. 


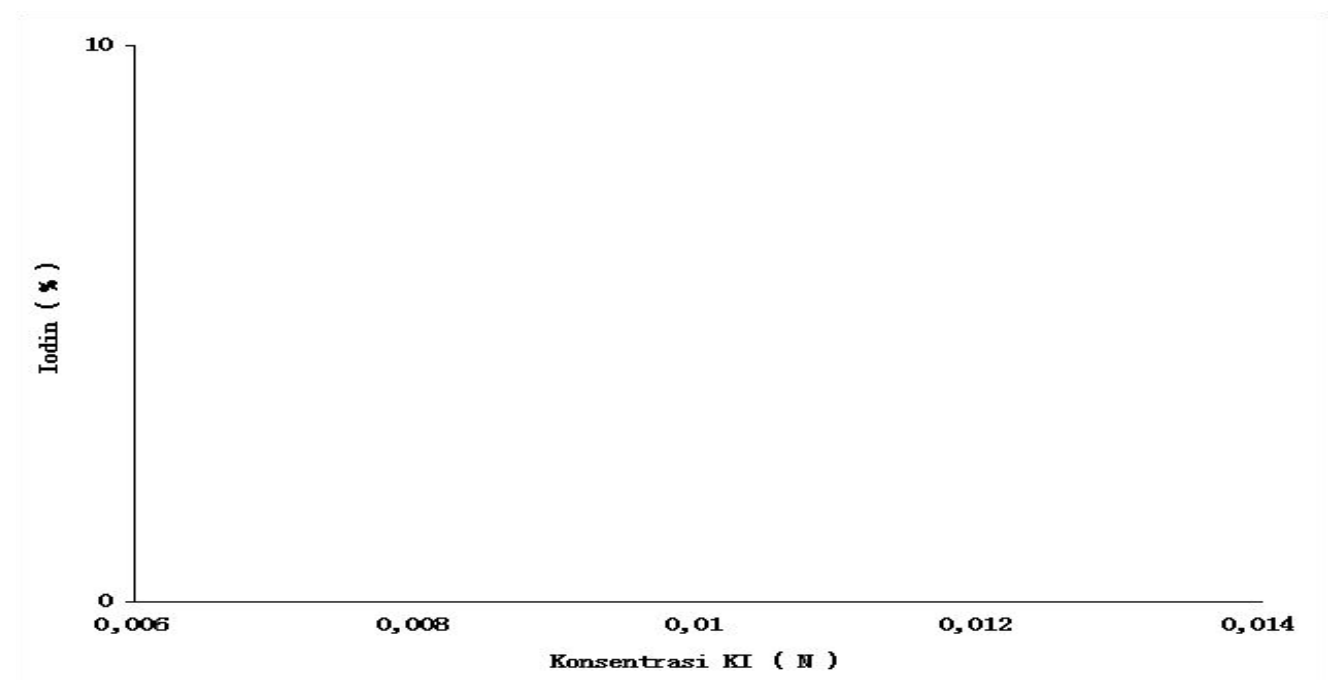

Gambar 3. Variasi perbandingan konsentrasi $I_{2}$ : KI di fasa sumber terhadap \% iodin yang diperoleh di fasa sumber $(\diamond)$ dan fasa penerima $(\mathbf{})$.

Kondisi percobaan : Fasa sumber $10 \mathrm{~mL}\left(\mathrm{I}_{2} / \mathrm{I}^{-}\right) \mathrm{pH}$ 4, fasa membran $30 \mathrm{~mL}$ kloroform, fasa penerima $20 \mathrm{~mL} \mathrm{Na} \mathrm{SO}_{3} 8 \times 10^{-3} \mathrm{~N}$ dan $\mathrm{NaOH}$ pH 9, waktu transpor 1 jam, dan waktu kesetimbangan 10 menit.

\section{Pengaruh waktu terhadap transpor iodin}

Faktor pengadukan sangat mempengaruhi interaksi tumbukan antar molekul dalam memperlancar terjadinya proses difusi ${ }^{[4,5,7]}$. Waktu transpor juga memberikan efek yang sangat nyata terhadap jumlah iodin yang tertranspor dari fasa sumber ke dalam fasa membran kemudian diteruskan ke fasa penerima. Dari penelitian yang telah dilakukan iodin dapat ditranspor ke fasa penerima sebesar $78,58 \%$ dengan waktu transpor optimum 180 menit.

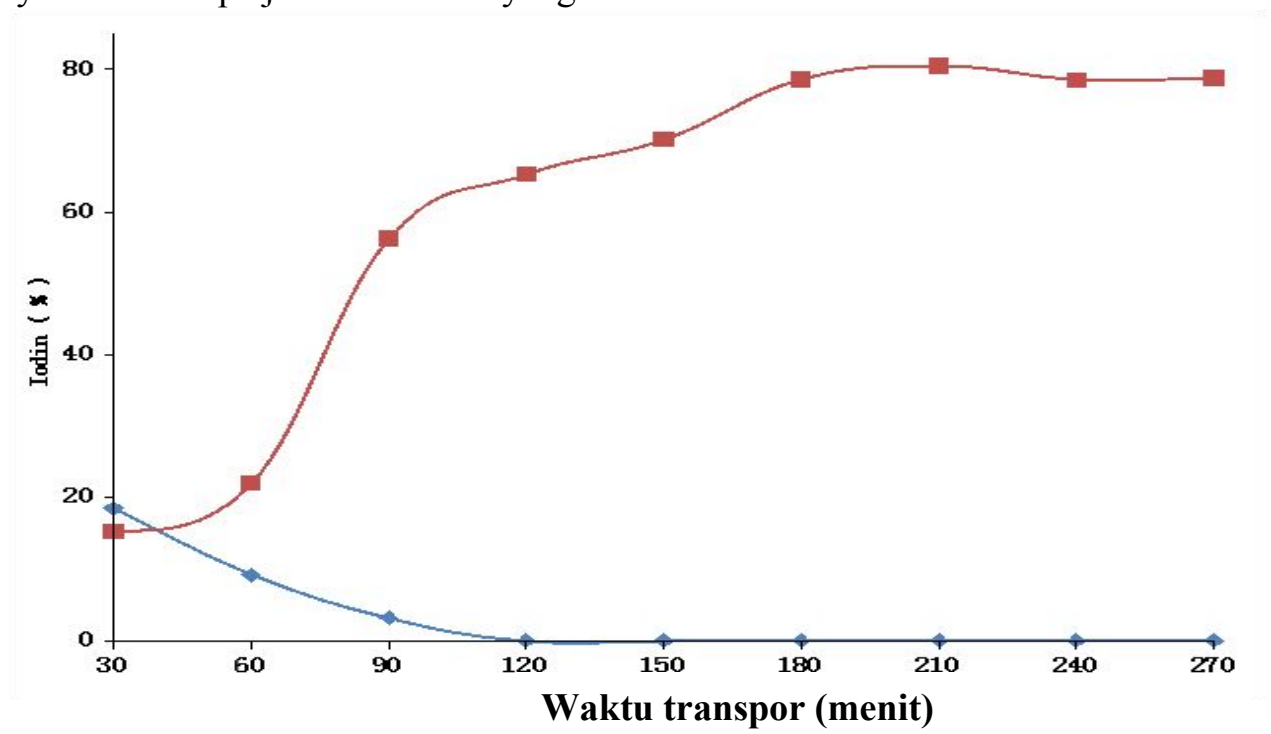

Gambar 4 : Variasi waktu transpor terhadap \% iodin yang diperoleh di fasa sumber $(\diamond)$ dan fasa penerima ( $\mathbf{\square})$.

Kondisi percobaan : Fasa sumber $10 \mathrm{~mL}\left(\mathrm{I}_{2} / \mathrm{I}^{-}\right)(2: 5) \mathrm{pH}$ 4, fasa membran $30 \mathrm{~mL}$ kloroform, fasa penerima $20 \mathrm{~mL} \mathrm{Na}_{2} \mathrm{SO}_{3} 8 \times 10^{-3} \mathrm{~N}$ dan $\mathrm{NaOH}$ pH 9, berbagai variasi waktu transpor, dan waktu kesetimbangan 10 menit. 
Gambar 4 dapat dilihat bahwa dari waktu 30 menit sampai dengan 180 menit transpor iodin ke fasa penerima semakin meningkat sedangkan sisa iodin di fasa sumbernya semakin menurun dan pada waktu transpor 120 menit iodin tidak terdeteksi lagi dalam fasa sumber. Iodin yang berada di fasa sumber berangsur-angsur berpindah/berdifusi ke fasa membran maksimal pada waktu 90 menit (membran berwarna pink pekat) dengan bertambahnya waktu transpor warna pink semakin memudar dan mencapai optimum pada waktu 180 menit. Pada waktu lebih besar dari 180 menit jumlah iodin tertranspor tidak memberikan kenaikan yang begitu nyata sampai dilakukannya variasi waktu selama 270 menit. Pengaruh waktu transpor memberikan perubahan yang nyata terhadap sistim membran. Warna kuning iodin yang berada di fasa sumber dengan bertambahnya waktu transpor semakin memucat, sedangkan kloroform yang bertindak sebagai membran lama kelamaan akan berwarna pink/merah jambu pekat dan juga akan memudar kembali. Namun, pada fasa penerima tidak mengalami perubahan warna seperti larutan di fasa sumber dan di fasa membran. Persentase iodin yang berhasil tertranspor ke fasa penerima dalam waktu optimum 180 menit adalah sebesar 78,58\%.

Adapun perkiraan mekanisme reaksi yang terjadi dalam proses transpor iodin ini adalah :

Fasa Sumber

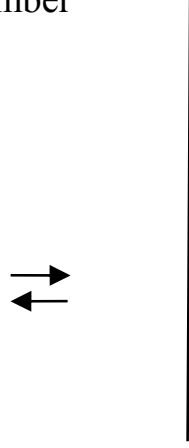

Fasa Membran

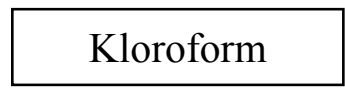

Fasa Penerima

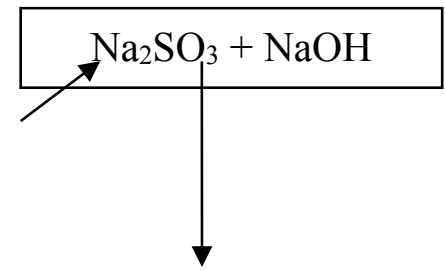

Gambar 5. Reaksi yang terjadi pada sistem transpor iodine.

Kemudian iodin yang terdapat di fasa penerima dalam bentuk $\mathrm{I}^{-}$ini dioksidasi oleh kalium persulfat, sehingga terbentuklah $\mathrm{I}_{2}$ dan dengan penambahan amilum larutan akan berwarna biru sehingga dapat diukur absorban dari larutan tersebut dengan menggunakan spektrofotometer UV-Vis. Rangkaian reaksi yang terjadi :

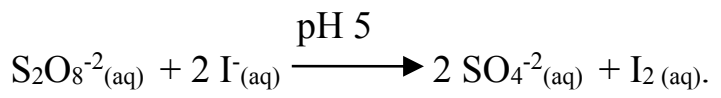

Dari reaksi terlihat bahwa kondisinya netral, tetapi pada saat pengujian dengan metode spektrofotometri diperoleh $\mathrm{I}_{2}$ maksimal pada $\mathrm{pH} 5$, sehingga untuk penentuan jumlah iodin yang tertranspor ke fasa penerima pendeteksiannya dilakukan pada $\mathrm{pH}$ tersebut di atas.

\section{KESIMPULAN}

Dari hasil penelitian yang telah dilakukan dapat disimpulkan bahwa transpor iodin melalui membran cair kloroform dan $\mathrm{Na}_{2} \mathrm{SO}_{3}$ dalam $\mathrm{NaOH}$ sebagai reagen striping dalam fasa penerima dengan kecepatan pengadukan $100 \mathrm{rpm}$ dapat mentranspor iodin secara optimal sampai ke fasa penerima dengan waktu transpor 180 menit (3 jam) jauh lebih cepat dibandingkan penelitian oleh Betsabe, dkk yaitu 28 jam. Kondisi optimum untuk sistem transpor iodin ini diperoleh pada $\mathrm{pH}$ larutan di fasa sumber 4, $\mathrm{pH}$ larutan fasa penerima (reagen striping) $\mathrm{Na}_{2} \mathrm{SO}_{3}$ dan $\mathrm{NaOH}$, dan perbandingan konsentrasi KI yang digunakan untuk melarutkan $\mathrm{I}_{2}\left(\mathrm{I}_{2}: \mathrm{KI}\right)$ di fasa sumber adalah $2: 5$. Pada kondisi ini hasil transpor maksimal iodin diperoleh sebesar 78,58\%. 


\section{DAFTAR PUSTAKA}

1. Falah, dan Miftahul. "Iodin (I) atau Yodium". (http://www.google.com.miftahul.wordpress.com),12/12/2010.

2. B. Nabieyan, A. Kargari, T. Kaghazchi, A. Mahmoudian, M. Soleimani, Benchscale pertraction of iodine using a bulk liquid membrane system, Desalination., (214): 167-176, (2007).

3. Departemen Kesehatan Republik Indonesia, Farmakope Indonesia, edisi IV : Depkes RI. 316-317 (1995).

4. Savafi and E. Shams, Selective and efficient transport of $\mathrm{Hg}$ (II) through bulk liquid membrane using methyl red as carrier, J, Membrane Sci., 144: 37-43, (1998).

5. M. Mulder, Basic Principle of Membran technology, Kluwer Academic Publisher, Dordrencht, 244-259, (1991).
6. R. A. Day, and A. L. Underwood, Analisis Kimia Kuantitatif. Edisi VI. Jakarta: Erlangga, (2002).

7. A. B. Richard, Chemical separation with liquid membrane, ACS, Symposium series 642, American Chemical Society., Washington DC, 1: 202, 1996.

8. Refinel, Optimalisasi transpor $\mathrm{Cu}(\mathrm{II})$ dengan zat pembawa metil merah melalui teknik membran cair fasa ruah, Proseding Semirata, FMIPA-Unja Jambi, 17-19 Juli 2005.

9. Refinel, Zaharasmi, dan Olly, Kinetika transpor $\mathrm{Cu}(\mathrm{II})$ oleh zat pembawa oksin dengan dan tanpa asam oleat melalui membran cair fasa ruah, Jurnal Riset Kimia., 2(2): 127-131, (2009).

10. Refinel, Zaharasmi, dan Olly, Kinetika dan selektifitas transpor $\mathrm{Cu}(\mathrm{II})$ antara fasa melalui membran cair fasa ruah dengan oksin sebagai zat pembawa, Jurnal Riset Kimia., 4(1): 63-72, (2010). 